\title{
Participar ou não participar, eis a questão! Um estudo sobre o engajamento dos estudantes de Administração em atividades extracurriculares
}

\author{
Fernanda Roda de Souza Araújo Cassundél ; Alania Caroline Gonçalves Bonfim dos Santos ${ }^{2}$; \\ Erika Naomi Muranaka ${ }^{3}$; Laura Almeida Nunes ${ }^{4}$; Rafael Nery Amorim ${ }^{5}$
}

Resumo: O presente trabalho tem como principal objetivo avaliar o envolvimento dos estudantes de administração da Universidade Federal do Vale Do São Francisco (UNIVASF) em atividades extracurriculares. De modo específico, buscou-se identificar quais as atividades complementares mais praticadas pelos estudantes atualmente, um vislumbre das dificuldades encontradas para a não participação, além de traçar o perfil dos alunos participativos e não participativos em tais atividades. A fim de averiguar tais questões foram aplicados questionários nas nove turmas existentes, coletando dados de 162 estudantes. Os resultados refutam a ideia de que eles são pouco participativos em atividades extracurriculares. As atividades com maiores participações são aquelas de curta duração como palestras, mesas redondas e encontros da área, de modo contrário o engajamento em projetos de iniciação científica ainda é muito modesto. Os motivos para a não participação são em grande parte por falta de tempo em decorrência de atividades laborais e, em segundo lugar, por falta de conhecimento da existência dessas atividades. Isso em virtude principalmente da falta de divulgação da instituição em geral, mas também pela tímida publicidade por parte dos idealizadores das atividades.

Palavras-chave: ensino e pesquisa em administração, atividades extracurriculares, ambiente universitário, curso de administração.

\section{Participate or not to participate, that is the question! A study on the engagement of Administration students in extracurricular activities}

\begin{abstract}
This study aims to evaluate the degree of involvement of the Federal University of São Francisco Valley (UNIVASF) business students in extracurricular activities. In a specific way, it tries to identify the most complementary activities practiced currently by these students, a glimpse of the difficulties in the nonparticipation, and outline the profile of who participates and those who don't in such activities. Its basis is on a theoretical discussion of several authors about the subject, including on the importance of participation in complementary activities, besides of the concept and the origin of the term. In order to investigate such issues, it was applied questionnaires in the nine existing classes, collecting data of 162 students. The results refute the idea that they are not very participative in extracurricular activities. The activities with the highest interest are those short-lived as lectures, round tables and meetings in the area, on the other side the engagement in scientific projects is still very modest. The reasons for non-participation are largely for lack of time because of their jobs and, secondly, for lack of knowledge of the existence of those activities. This happens mainly due to the lack of disclosure of the institution in general, but also because of the timid advertising by the creators of the activities.
\end{abstract}

Keywords: teaching and research in management, extracurricular activities, college environment, business administration course.

\footnotetext{
${ }^{1}$ Professora do Colegiado de Administração da Universidade Federal do Vale do São Francisco - UNIVASF. Possui graduação e mestrado em Administração pela UFPE. Doutoranda em Administração pelo Programa de Doutorado Interinstitucional UNIVASF-UFPE/PROPAD. E-mail: fernanda.roda@univasf.edu.br.

Lattes: http://lattes.cnpq.br/2696430100313826.

Aluna do curso de graduação em administração da Universidade Federal do Vale do São Francisco - UNIVASF. E-mail: alaniacaroline@gmail.com.

${ }^{3}$ Aluna do curso de graduação em administração da Universidade Federal do Vale do São Francisco - UNIVASF.

E-mail: erika_naomimuranaka@hotmail.com...

${ }^{4}$ Aluna do curso de graduação em administração da Universidade Federal do Vale do São Francisco - UNIVASF.

E-mail: laura_nunes@gmail.com.

${ }^{5}$ Aluno do curso de graduação em administração da Universidade Federal do Vale do São Francisco - UNIVASF.

E-mail: rafaelnery182@gmail.com .
} 


\section{Introdução}

Os cursos de graduação em Administração apresentam um longo percurso de evolução no Brasil. Desde a criação do primeiro curso, por volta de 1902, até os dias atuais, com a expansão em massa das escolas de Administração, a formação dos administradores tem sido pautada nos velhos modelos de organização, assentada em valores e princípios comprometidos tão unicamente com a dimensão econômica. A estrutura dos cursos de graduação em Administração apresenta características excessivas de tecnicismo e de fragmentação do conhecimento em inúmeras disciplinas.

O problema da formação do profissional em Administração se agrava à medida que o processo de modernização, por que passa a sociedade brasileira, intensifica-se. O mercado está começando a exigir um administrador que seja capaz de articular todos os conhecimentos apreendidos nas salas de aula da universidade a fim de tomar as melhores decisões quando inserido em um ambiente turbulento e em rápida mutação, mais ainda, que seja capaz de romper com as antigas regras de um país onde a concorrência e o risco não faziam parte dos negócios.

Desse modo, é possível dizer que a tríade ensino, pesquisa e extensão é de grande importância para a formação dos estudantes de graduação. Cada vez fica mais claro para discentes e docentes que o processo de aprendizagem é muito mais eficaz quando não está limitado apenas aos recursos tradicionais de ensino. A lei $\mathrm{n}^{\circ}$ 9394/96 que estabelece as diretrizes da educação nacional expõe claramente a importância do componente extracurricular na educação, ao expor como princípio a "valorização da experiência extraescolar" (Art. 3, inciso X). Seguindo essa lei os cursos de graduação do Brasil devem apresentar planos de ensino que visem atingir essa expectativa. O Projeto Pedagógico do curso de Administração da Universidade Federal do Vale do são Francisco (UNIVASF) não é indiferente a isso, ele presa pela experiência extramuros e se pauta na tríplice de princípios norteadores da "indissociabilidade entre ensino, pesquisa e extensão". Nele pode ser verificado a proposta de estimular a "interdisciplinaridade e valorização da experiência extraescolar".

A partir de uma visão empírica sobre a participação dos estudantes de administração da UNIVASF em atividades extracurriculares (ou complementares), presume-se que a grande maioria não está ativamente engajada nas mesmas. Isso, provavelmente, pela própria característica do curso noturno - voltado para estudantes já inseridos no mercado de trabalho ou por deficiência nos mecanismos de divulgação e incentivo por partes dos idealizadores das atividades, dos professores, do colegiado e da própria instituição em geral.

A presente pesquisa tem, portanto, finalidade comprovar ou refutar a ideia de que os estudantes de graduação em Administração da UNIVASF são, em sua grande maioria, pouco participativos em atividades extracurriculares. A fim de avaliar o grau de engajamento desses estudantes em tais atividades foram aplicados questionários em uma amostra de aproximadamente 180 estudantes (sendo válidos apenas 162), de modo a identificar quais atividades extra ensino apresentam maior 
participação atualmente e obter um vislumbre das dificuldades encontradas para a não participação, bem como traçar o perfil dos estudantes participativos e não participativos. Por atividades extracurriculares foram considerados projetos de pesquisa e iniciação científica, projetos de extensão, estágio extracurricular, monitoria, tutorial especial de nivelamento, participação em palestras, mesas redondas, congressos, oficinas e cursos, encontros da área de Administração, simpósios, empresa júnior, SCIENTEX, entre outros.

\section{Discussão Teórica}

\section{O curso de graduação em Administração: panorama geral}

Os primeiros cursos de Administração no Brasil datam do ano de 1902, cujo ensino era realizado por duas escolas particulares, a Álvares Penteado, no Rio de Janeiro, e a Academia de Comércio, em São Paulo.

"Durante mais de seis décadas, o ensino das Ciências Administrativas se confundiu com o ensino das Ciências Econômicas, até a definição do currículo mínimo do curso de graduação em Administração" (NICOLINI, 2002, p.1). A regulamentação do ensino de Administração só aconteceu em 1931, após a criação do Ministério da Educação e a estruturação do ensino (NICOLINI, 2001). Também em 1931 é criado o Instituto de Organização Racional do Trabalho (IDORT), cujo objetivo era o de divulgar os teóricos e os métodos da Administração Científica e Clássica.

Diante da necessidade de mão-de-obra cada vez mais qualificada para lidar com uma burocracia especializada, a formação do Administrador foi começando a ganhar contornos mais claros, no Brasil, no início da década de 40 (ANDRADE, 2001). Neste período é criada a primeira escola de Administração do país, a Escola Superior de Administração e Negócios, em São Paulo (NICOLINI, 2002).

Um marco para o desenvolvimento do ensino de Administração foi através da criação da Fundação Getúlio Vargas (FGV), em 1944, cujo objetivo era formar profissionais especialistas para a Administração Pública e Privada. A Escola Brasileira de Administração Pública (EBAP) foi fundada logo após a FGV, em 1952, no Rio de Janeiro, para preparar profissionais apenas para a área pública.

Atendendo às expectativas do empresariado local, a FGV criou a Escola de Administração de Empresas de São Paulo (EAESP). Esta escola destinou-se a formar profissionais especialistas nas modernas técnicas de gerência empresarial na capital econômica e coração da iniciativa privada do país (NICOLINI, 2001). 
Se o surgimento do ensino de Administração é resultante do desenvolvimento econômico do governo de Getúlio Vargas, um grande incentivo dado à expansão desse ensino foi o surto industrializante no qual ingressou o país sob o comando de Juscelino Kubitschek, décadas mais tarde, que havia criado uma enorme demanda por profissionais que pudessem atuar nas organizações que se instalavam e progrediam, no ambiente de intensas mudanças econômicas que vinham ocorrendo (NICOLINI, 2001, p.3).

A regulamentação da profissão, no entanto, só ocorreu em meados dos anos sessenta, com a Lei 4.769, de 09 de setembro de 1965; os profissionais da área receberam o nome de Técnicos em Administração; mas, foi somente através do parecer n n 307/66, aprovado em 08 de Julho de 1966, um ano seguinte à regulamentação da profissão, que o Conselho Federal de Educação fixou o primeiro currículo mínimo e o tempo de duração para o curso de Administração.

Com a aprovação, pelo Conselho Federal de Educação, em 4 de outubro de 1993, o novo currículo mínimo passa a ser o grande desafio das universidades, que, a partir de então, tiveram que oferecer uma "formação mais próxima da generalista, ao assumir a condição da Administração como uma ciência social aplicada" (NICOLINI, 2002).

\section{Sobre as atividades extracurriculares e sua importância na formação docente}

Em um momento de mudanças, é fundamental que se possa contar com administradores cuja capacidade seja a de romper com as antigas regras de um país onde a concorrência e o risco não faziam parte dos negócios. "O país requer administradores aptos a gerenciar a crise e garantir a democracia, em uma economia moderna" (FISCHER, 1993, p.16). Neste contexto, os velhos modelos de organização e gerência do trabalho, fundamentados nos princípios da Administração Científica, cujas bases remontam à Revolução Industrial, já não atendem mais às exigências do mercado, salienta Nicolini (2001). Historicamente, de acordo com Corrêa (2001), o modelo do administrador foi se configurando com maior ênfase no âmbito da racionalidade técnica e no uso da racionalidade instrumental. Esta caracterização orientou e sustentou, por décadas, a formação de profissionais assentada em valores e princípios comprometidos tão unicamente com a dimensão econômica. Desse modo, é possível perceber que a estrutura dos cursos de graduação em Administração foi dominada pelo excesso de tecnicismo, tornando rapidamente arcaico os programas deste curso. E, consequentemente, por estes cursos estarem ligados à escolas isoladas e sem produção científica, tornou a atualização curricular uma prática não muito constante (Motta 1983 apud NICOLINI, 2002). "Mesmo nas melhores escolas do Brasil os programas lembram cursos norte-americanos da década de 60" (Motta, 1983, p.53 apud NICOLINI, 2002, p.4). Neste sentido, Birochi (2000, p.83) complementa que "é neste contexto de profundas mudanças da realidade e de seu consequente reflexo nas estruturas 
estabelecidas da aprendizagem que surge uma proposta de construção de uma nova organização curricular do ensino superior".

É preciso mencionar que, foi somente através do parecer $n^{\circ}$ 307/66, aprovado em 08 de Julho de 1966, um ano seguinte à regulamentação da profissão, que o Conselho Federal de Educação fixou o primeiro currículo mínimo e o tempo de duração para o curso de Administração.

Segundo Guerra (2001), não é mais esperado do curso de graduação em Administração a formação de profissionais que respondam somente às necessidades do mercado, ou seja, o administrador, como acontecia antigamente, não deve ser treinado com vistas apenas à solução de problemas, espera-se mais de um profissional em um mundo em transformação constante. Ao invés de treiná-lo para dar respostas prontas aos problemas rotineiros, deve-se educá-lo para desafios maiores. Assim sendo, passa a ser importante que os cursos de graduação em Administração, neste novo contexto, não privilegiem apenas as técnicas "necessárias e nem ao menos transmitam aos seus discentes somente as fórmulas prontas, mas que estejam preocupados também em trazer o lado crítico, dando aos discentes a possibilidade de aprender a aprender", afirma Spers (2001, p.15-16).

A educação se mostra como uma das principais bases para uma boa entrada no mercado de trabalho. A Lei $\mathrm{n}^{\circ}$ 9.394/96 contendo as Diretrizes e Bases da educação nacional estabelece no capítulo IV art. 43 inc. I e II que educação superior deve "estimular a criação cultural e o desenvolvimento do espírito científico e do pensamento reflexivo" e "formar diplomados nas diferentes áreas de conhecimento, aptos para a inserção em setores profissionais e para a participação no desenvolvimento da sociedade brasileira, e colaborar na sua formação contínua". Contudo existem algumas lacunas entre as duas esferas, principalmente da parte dos cursos de graduação, na busca pela integração entre a teoria proporcionada pelas Instituições de Ensino Superior - IES e as imposições do mercado de trabalho. Há muitas queixas por parte dos estudantes a respeito disso, alegando a falta de preparo para a inserção no mercado trabalhista ao finalizarem seus cursos de graduação.

Na busca pela diminuição desses conflitos as IES e o Ministério da Educação vêm dando ênfase nas experiências das atividades extracurriculares que, além de possuírem um aspecto mais específico, também permitem simular a participação no mercado de trabalho e favorecer trocas de conhecimento e experiências com a sociedade. Arroyo e Rocha (2010) destacam bem a importância das universidades no ensino fora da sala de aula, para ele:

[...] a missão e razão de existência das universidades está em produzir e difundir o conhecimento, com objetivos mais ambiciosos do que os propostos para os níveis fundamental e médio. Conforme Silva (2000, p.43), esta difusão de conhecimento se organiza em duas etapas: "intramuros", operacionalizada através das atividades realizadas internamente nos ambientes universitários, portanto, principalmente através das ações de ensino; e "extramuros", direcionadas aos grupos que não pertencem aos corpos docente e discente da instituição universitária; portanto, através das ações de extensão. (ARROYO e ROCHA, 2010, p.137). 
As atividades extracurriculares, de modo geral, englobam projetos de iniciação científica e de extensão, empresa júnior, participação em eventos da área (congressos, simpósios, oficinas e workshops), etc. Para Peres et al (2007) "as atividades extracurriculares podem ser entendidas como aquelas que não são concebidas com características obrigatórias, mas se encontram sob a responsabilidade da instituição e fazem parte do currículo de formação". Iamamoto (2000) complementa essa definição ao conceber as atividades extracurriculares como:

[...] o conjunto de atividades desempenhadas pelas universidades voltadas a transmissão de conhecimentos, à prestação de serviços e à difusão cultural. Além de uma concentrada oferta de serviços, conhecimentos e eventos, propõe-se redimensionar a extensão como processo educativo, cultural e científico, que articula a universidade com as necessidades dos segmentos majoritários da população, viabilizando uma ação transformadora entre a universidade e a sociedade na formação de profissionais cidadãos. (IAMAMOTO, 2000)

O termo "extensão", no âmbito das IES, surgiu na legislação educacional nacional em 1931 por meio do primeiro Estatuto das Universidades Brasileiras, referindo-se ao oferecimento de cursos e conferências de caráter educacional como "organismo da vida social da Universidade" (SOUSA, 2000, p. 16). Posteriormente ressurgiu no então texto da Lei $n^{\circ} 5.540 / 68$ tornando-o obrigatório em todas as Instituições de Ensino Superior do Brasil.” (ARROYO; ROCHA, 2010, p. 137).

Segundo o MEC - Ministério da Educação - não existe um critério específico acerca da formação curricular do estudante, cabendo a cada IES definir o seu próprio programa, elaborar e divulgar as propostas curriculares de cada curso, levando em consideração aspectos como flexibilidade, responsabilidade e criatividade. O que é de fato importante é que essas propostas obedeçam às diretrizes curriculares nacionais estabelecidas pelo MEC, dentre as quais estão inclusas as ações de ensino complementares ao currículo do estudante. Ou seja, o MEC permite uma flexibilidade quanto à definição de atividades complementares por parte de cada IES, contudo pode-se observar que a variação das atividades oferecidas por cada curso não é muito diferente. Exemplo é o curso de administração, em que a maioria das IES possui em comum ações como empresas júnior, estágios extracurriculares, projetos de extensão, programas de iniciação científica e outros. Entretanto a diferença está na obrigatoriedade ou não dos estudantes participarem de tais atividades, como é o caso do curso de administração em instituições como a UNIVASF e a Universidade de São Paulo, cuja escolha de participar ou não das atividades fora da grade curricular caberá ao discente. Já em outras instituições os processos extramuros de aprendizado as têm como pré-requisitos para a conclusão do curso, a exemplo da Fundação Getúlio Vargas que possui um dos melhores cursos de administração do Brasil.

Há uma diversidade de níveis de participação dos estudantes a depender da instituição em que os mesmos estão inseridos, ainda assim parece claro entre os estudiosos que o fato de se envolver nessas ações extramuros tem saldo positivo. Em um estudo realizado com jovens em vias de conclusão 
de curso, Teixeira e Gomes (2004) concluíram que o envolvimento dos estudantes em sua formação especialmente em atividades práticas, como os estágios não obrigatórios - reforça o senso de competência. Além disso, a participação em atividades acadêmicas (monitorias, estágios extracurriculares) e a identificação com a profissão são consideradas comportamentos exploratórios fundamentais para a elaboração de projetos realistas em relação à futura atuação na profissão escolhida. (BARDAGI, LASSANCE; PARADISO, 2003). Segundo Pedro Faria dos Santos ${ }^{1}$, do departamento de Química da Unicamp (Universidade Estadual de Campinas) e supervisor da Empresa Junior: "O estudante sente-se mais confiante e mais bem preparado, com a facilidade para trabalhar em equipe, com pró-atividade e criatividade para lidar com dificuldades".

Essas competências adquiridas por meio de envolvimentos complementares além das tradicionais de ensino são enriquecedoras, em especial no curso de administração, tendo em vista que o aluno terá de lidar com diferentes situações práticas, tais como analisar relatórios financeiros, gerir pessoas, saber negociar e atém mesmo no envolvimento político-econômico-social do país. Por esse motivo, as atividades extras propostas e realizadas pelas IES são importantes, tanto que Severino (2009) ressalta que "a universidade como instituição e como lugar específico do ensino superior é responsável por se dedicar à formação do cidadão autêntico, pois seu papel mais substantivo vai muito além da formação do profissional, do técnico e do especialista".

Ademais as atividades complementares também possuem um caráter social em razão de sua finalidade mais voluntária do que lucrativa. A importância na participação nessas atividades vai além do aspecto da experiência individual e social, voltando-se também para a promoção da cidadania. Segundo Pozzobon e Buzzato (2009, p. 2): "a identidade da universidade é abrir-se para o mundo social no qual se requer a valorização da extensão como ação comunicativa, com o objetivo prático das ciências em comunicação, o local de encontro com a comunidade externa de busca e elaboração de diálogos com novos parceiros".

Apesar da participação em atividades extracurriculares ser mais expressiva em cursos da área de saúde e exatas nas universidades brasileiras, os cursos da área de humanas tem obtido um significativo avanço em termos de envolvimento, especialmente no curso de administração, sendo propulsoras de novas experiências.

Apesar da importância dessas atividades - não somente para benefício próprio, mas também para o coletivo e o desenvolvimento da cidadania local - a maioria dos alunos enfrenta dificuldades para a participação. Por esse motivo, esse presente estudo tem como fundamental intuito analisar o grau de participação dos estudantes de administração da UNIVASF em tais atividades e obter um vislumbre do porquê de suas dificuldades.

1 Cf. Profissionalismo começa dentro da faculdade, Revista Agitação/CIEE, no 40, de julho/agosto, de 2001, p.28.

48 Id en line Revista de Psicologia. Ano 9, No. 26, Supl. Esp. Abri//2015 - ISSN 1981-1179. Edição eletrônica em http://idonline.emnuvens.com.br/id 


\section{Design da Pesquisa}

Este trabalho caracteriza-se por ser um estudo que permitiu avaliar o envolvimento dos estudantes de administração da Universidade Federal do Vale Do São Francisco (UNIVASF) em atividades extracurriculares. Apresenta-se uma metodologia de caráter descritivo e explicativo, propondo-se a realizar descrições precisas da situação e descobrir as relações existentes entre os elementos componentes da mesma (CRESWELL, 2010).

A amostra estabelecida para este estudo foi calculada a partir dos 421 alunos atualmente matriculados no curso de Administração da UNIVASF, e considerando-se 68\% de representatividade (RICHARDSON, 2007). Neste sentido, foram entrevistados um total de 162 estudantes divididos entre as nove turmas existentes.

Para fins de instrumento de coleta de dados, foi utilizado um questionário. As variáveis consideradas para análise incluem as pertinentes para identificar o perfil dos participantes e não participantes (idade, sexo, estado civil, se tem filhos, período de ingresso), bem como breves opiniões acerca da importância das atividades extracurriculares, da qualidade das mesmas e se há divulgação suficiente para o conhecimento delas. A fim de identificar quais as atividades que os alunos já participaram ou estão participando foram listadas as principais existentes na instituição e as mais frequentemente disponíveis (PIBIC, PIBEX, PIVIC, SCIENTEX, monitoria, tutoria especial de nivelamento, estágio extracurricular, palestras, mesas redondas e encontros de administração, projetos de extensão, workshops, oficinas, cursos, simpósios, empresa júnior e outros). Também foi levada em consideração a existência de estudantes que jamais participaram de quaisquer atividades.

Referente ao perfil dos estudantes partiu-se do pressuposto de que o fato de trabalhar poderia influir na participação ou não. A aplicação por turma foi necessária para desmitificar (ou não) que estudantes nas mais avançadas conhecem mais a respeito das atividades existentes e por esta razão podem ser mais participativos.

A análise de dados foi feita utilizando-se programa específico para análise estatística nas Ciências Sociais.

\section{Razões para a escolha da IES e do curso}

Foi escolhido como lócus deste estudo a Universidade Federal do Vale do São Francisco (UNIVASF) e, como unidade de análise, o curso de Administração. É importante salientar que a escolha por esta IES considerou o critério de acessibilidade dos pesquisadores, do impacto regional, local e nacional que esta IES apresenta. 


\section{Sobre a Universidade Federal do Vale do São Francisco e o Curso de Administração}

Criada no início dos anos 2000 e legitimada pela Lei $n^{\circ} 10.473$ de 27 de Junho de 2002, a Universidade Federal do Vale do São Francisco foi escolhida como lócus deste estudo.

Com sede na cidade de Petrolina (Pernambuco), a UNIVASF tem o semiárido nordestino e o Vale do São Francisco como referenciais de atuação, uma região abrangida por "um raio de 250 quilômetros, centrado nas cidades de Petrolina e Juazeiro, englobando um total de 74 municípios em três estados do Nordeste, sendo 35 na Bahia, 30 em Pernambuco e 9 no Piauí" (UNIVASF, 2008, p.13). É a única universidade federal do país criada nas últimas décadas com missão de desenvolvimento regional e com estrutura multi-campi em três estados diferentes: Pernambuco, Bahia e Piauí.

Na região de Petrolina/PE-Juazeiro/BA predomina o agronegócio e o cultivo, dentre outras frutas, de manga e uva. O pólo Petrolina/Juazeiro representa o maior centro produtor de mangas do país, uma referência em fruticultura irrigada (CASSUNDÉ JUNIOR; LIMA; PIMENTEL, 2006), sua participação é correspondente a aproximadamente $80 \%$ do total das exportações, feita pelo Brasil, desta fruta para o mercado internacional em 2010. Esta atividade da economia apresenta-se como uma grande geradora de empregos, sendo responsável por 240.000 empregos diretos e 960.000 empregos indiretos na região, a estimativa é que sejam gerados, em média, 2 empregos por hectare irrigado (MACIEL, 2011).

Deste cenário nasceu o curso de Administração da UNIVASF. Seu início foi em conjunto com o das atividades acadêmicas da instituição, que ocorreu em outubro de 2004, a partir do ingresso dos alunos em dez cursos de graduação (Administração, Enfermagem, Engenharia Agrícola, Engenharia Ambiental, Engenharia Civil, Engenharia Elétrica, Engenharia Mecânica, Engenharia de Produção, Medicina e Zootecnia) provenientes do primeiro processo seletivo vestibular.

Inicialmente, o curso de Administração da UNIVASF foi concebido para oferecer três habilitações: agronegócio, comércio exterior e turismo e hotelaria. Porém, em função de uma adequação da matriz curricular e de um perfil mais atual sugerido pelo MEC, pelo Conselho Federal de Administração (CFA) e pela Associação Nacional dos Cursos de Graduação em Administração (ANGRAD), o curso de Administração da UNIVASF promoveu um redirecionamento e uma adequação da matriz de disciplinas e ementários, sem perder, no entanto, o foco nas particularidades regionais e necessidades sociais e econômicas do contexto em que está inserido (UNIVASF, 2008).

Em 2012, a UNIVASF, através de sua Secretaria de Educação a Distância, aprovou na Coordenação de Aperfeiçoamento de Pessoal de Nível Superior (CAPES) sua adesão aos cursos do Programa Nacional de Formação em Administração Pública (PNAP) na modalidade a distância. São 925 vagas distribuídas em cursos da área de Administração na modalidade a distância (bacharelado em 
Administração Pública e pós-graduação a nível de especialização em Gestão Pública, Gestão Pública Municipal e Gestão em Saúde).

Atualmente, portanto, a UNIVASF conta com cursos de Administração, em nível de graduação na modalidade presencial e a distância, e em nível de pós-graduação na modalidade a distância.

\section{Análise dos Dados}

O presente estudo tem como base uma população de 421 alunos atualmente matriculados no curso de administração da UNIVASF, dos quais 162 contribuíram para esta investigação. A fim de obter um vislumbre da situação em termos de participação em atividades extracurriculares e responder ao questionamento central da pesquisa, os questionários aplicados levaram em consideração as seguintes questões: idade, sexo, estado civil, se tem ou não filhos, opinião sobre a contribuição das atividades complementares para a formação profissional, se as atividades da instituição têm ou não divulgação suficiente, as atividades que já participaram ou estão participando, se nunca participaram de nenhuma, avaliação da experiência propiciada pelas atividades que já estiveram envolvidos, o motivo da não participação e se tivessem disponibilidade participariam de alguma. As atividades listadas foram PIBIC, PIBEX, PIVIC, SCIENTEX, monitoria e tutoria especial de nivelamento, estágio extracurricular, palestras, mesas redondas, encontros de administração, projetos de extensão, workshops, oficinas, cursos, congressos, simpósios e empresa júnior.

O ponto central da pesquisa está em responder se os alunos desse curso são participativos em atividades extracurriculares. De modo específico, buscou-se conhecer o perfil geral da amostra, uma breve opinião sobre a importância da participação, se acreditam que há divulgação suficiente (em caso negativo, falta promoção por parte de quem?), bem como verificar as atividades com maior participação e o perfil de quem participa. Além disso, também foi necessário obter um parecer das dificuldades daqueles que não participam (ou participaram) de quaisquer atividades.

Com base nisso temos, primeiramente, como perfil dos respondentes que a média de idade para ambos os sexos está em torno de 25 anos, as idades mais frequentes foram 23 e 24 anos correspondendo juntas a $23,3 \%$ do total da amostra. Há uma predominância de pessoas solteiras $(74,7 \%)$ - embora haja um percentual significativo de casados $(19,6 \%)$, ao passo que um número pequeno de pessoas com filhos $18,6 \%$, além de uma considerável parcela, $51 \%$ dos respondentes, pertencente ao sexo masculino.

Com a análise dos dados observou-se que alunos nas idades de 23, 24 e 25 anos são os que mais participaram das atividades extracurriculares, sendo o sexo masculino o de maior público. Das nove turmas existentes no curso, verificou-se que as de maior participação nas práticas 
extracurriculares foram as turmas do $9^{\circ}$ e $7^{\circ}$ períodos, sendo a de menor a do $4^{\circ}$ período. Este último fato pode ser explicado muito provavelmente pelo maior percentual de pessoas que trabalham está nesse semestre.

A seguir, a tabela de Participação por atividade dentre o total de participações em \%.

Tabela 1: Participação por atividade dentre o total de participações em \%

\begin{tabular}{r|c}
\hline Descrição da atividade complementar & \% de participações \\
\hline Palestras, mesas redondas, encontros na área & 23,2 \\
\hline Oficinas e cursos & 17,6 \\
\hline SCIENTEX (Semana de ensino, pesquisa e extensão) & 10,5 \\
\hline Estágio extracurricular & 10,2 \\
\hline Congressos e simpósios & 9,9 \\
\hline Workshops & 9,7 \\
\hline Projetos de extensão & 6,6 \\
\hline Empresa júnior & 3,8 \\
\hline MIBIC (Programa Institucional de Bolsas de Iniciação Científica) & 2,3 \\
\hline PIBEX (Programa Institucional de Extensão) & 1,8 \\
\hline BIA (Bolsa de Incentivo Acadêmico) & 0,8 \\
\hline PIVIC (Programa Institucional Voluntário de Iniciação Científica) & 0,5 \\
\hline FONTE: elaboração própria & Outros
\end{tabular}

Na tabela 01, é possível identificar que as atividades extracurriculares de maior participação são as palestras, mesas redondas e encontros da área, correspondendo a $23,2 \%$ do total de participações e em segundo lugar as oficinas e cursos com 17,6\% de envolvimento. Um fato bastante curioso diz respeito ao mínimo percentual de estudantes atuando nos programas de iniciação científica, com um percentual de apenas $2,47 \%$ dos alunos que no momento da pesquisa estavam empenhados em tais projetos. Programas de iniciação esses entendidos, segundo a Resolução 03/2009 do Conselho Universitário da UNIVASF, como PIBIC e PIVIC.

Por outro lado $22,8 \%$ das pessoas assumiram não ter participado de nenhuma atividade. Dentre os motivos para a não participação está no fato de que $25,3 \%$ dos estudantes da amostra analisada afirmarem não participar de algumas ou de todas as atividades devido à falta de tempo disponível ocasionada pelo trabalho e $10 \%$ alegou não participar por desconhecer a existência delas. Em contrapartida $72,84 \%$ da amostra confessou que se tivesse tempo disponível fariam alguma atividade complementar, pois acredita que poderia ganhar ainda mais experiência profissional se participassem de alguma.

Dentre as 37 pessoas $(22,8 \%)$ que afirmaram jamais ter se envolvido com atividades extra ensino: $59,5 \%$ pertenciam ao sexo masculino, $70,3 \%$ das pessoas eram solteiras contra apenas $24,3 \%$ de casadas, 70,3\% respondeu não ter filhos. Outro ponto com relação ao perfil dos não participativos é que $64,9 \%$ deles estão entre a faixa etária de 19 a 24 anos ou com exatos 27 anos de idade. 
Dentre os alunos que participaram de quaisquer atividades, 73,7\% avaliou que a experiência providenciada pela atividade de extensão foi boa, ainda que houvesse algumas pequenas deficiências as fariam novamente se o tema fosse interessante. Já outros $22 \%$ disseram que a experiência foi excelente e que participaram novamente de outras atividades.

A grande maioria $(91,4 \%)$ diz acreditar que o conhecimento e a experiência que adquiriu (ou adquirirá) ajudou (ou ajudará) muito na construção da vida profissional. Contudo a $87,6 \%$ afirmou que atividades extramuros da UNIVASF não têm divulgação suficiente para que os estudantes cheguem a ter conhecimento delas. Além disso, $73 \%$ deles acham que isso se deve em grande parte à falta de divulgação por parte da instituição em geral e 17\% acredita ocorrer em razão do pouco ou não empenho dos idealizadores em promover a divulgação da ação não curricular. Apesar disso, os dados amostrais revelam que a participação é bastante significativa nesse curso, pois $77,2 \%$ afirmou já ter participado (ou está participando) de pelo menos uma atividade extracurricular.

\section{Conclusões}

O Brasil vive, desde o início dos anos 90, um período de intensas mudanças: privatizações e concessões nas áreas em que antes atuava apenas o Estado, incorporações de empresas nacionais por empresas estrangeiras, fusões de empresas brasileiras com outras a fim de enfrentar a concorrência global. Diante desse processo de modernização, que a sociedade brasileira vem passando, um dos principais requisitos é o equacionamento das questões educacionais, em todos os níveis do país.

Diante do novo cenário brasileiro, as organizações necessitam de administradores aptos a gerenciar a crise e garantir a democracia, em uma economia moderna. Assim sendo, os velhos modelos de organização e gerência do trabalho, fundamentados nos princípios da Administração Científica, cujas bases remontam à Revolução Industrial, já não atendem mais às exigências do mercado.

Neste contexto de mudanças, o conhecimento em Administração está passando por aceleradas transformações, impondo, de certa forma, que o futuro administrador seja incentivado a romper paradigmas, a criar e ousar em um mundo de complexidade crescente e que se transforma rapidamente.

A partir dos resultados analisados observou-se que, na realidade, os estudantes do curso de administração da UNIVASF são sim participativos nas atividades complementares $(77,2 \%)$, de modo que a minoria nunca participou de nenhuma (22,8\%). Os motivos que explicariam essa alta participação estão no fato de que a maioria dos discentes $(91,5 \%)$ acredita que a experiência ganha com essas atividades colabora com a inserção no mercado de trabalho, incluindo a parcela que disse 
não possui tempo o suficiente para praticá-las. Outro ponto está na existência de um feedback positivo quanto à experiência que a atividades extracurriculares propiciaram.

As atividades de maior participação são aquelas de curta duração tais como palestras, mesas redondas e encontros de administração. Tendo elas um público predominantemente masculino com média de idade de 25 anos e de pessoas solteiras. De fato os mais participativos estão em turmas mais avançadas, evidenciando que o conhecimento acerca das atividades existentes ocorre ao longo da vivência na graduação.

A participação em projetos de iniciação científica, por outro lado, ainda é muito acanhada. Isso provavelmente em razão da resolução 03/2009 - que trata das normas do programa de iniciação científica da UNIVASF - proibir a participação de alunos com qualquer vínculo empregatício ou de estágio (com ou sem remuneração), sejam eles os titulares do projeto ou até mesmo os voluntários (mesmo que disponham de carga horária livre).

Assim como a iniciação científica, poucos foram aqueles que participam ou participaram de empresa júnior ou qualquer outra que forneça a prática necessária requisitada pelo mercado de trabalho. Outra questão interessante está no fato de que muitos dos que trabalham não ter assinalado que as atividades desenvolvidas em seus ambientes laborais já propiciarem a experiência necessária para sua formação como administrador.

O perfil geral dos não participativos pode ser descrito como de predominância de pessoas solteiras, sem filhos, majoritariamente masculina e sendo em sua grande maioria os mais jovens do curso. Isso exclui a possibilidade de que a responsabilidade por filhos ou pela família (quando casados) mina a possibilidade de participação.

Por esses motivos, conclui-se que os estudantes de administração da UNIVASF possuem um alto grau de envolvimento em atividades extracurriculares em especial as de curta duração e um retraído envolvimento em projetos de iniciação científica. Ou seja, as atividades extracurriculares são percebidas pela maioria dos discentes como um exercício presente no dia a dia da Universidade.

O acompanhamento da percepção do aluno na construção do conhecimento, a partir de ações investigativas desenvolvidas pela Instituição durante o decorrer do curso de Administração, é uma forma de mensurar o quão eficaz está sendo a metodologia utilizada para o desenvolvimento dos futuros profissionais no que concerne à experiência acadêmica e a inserção e fixação no mercado de trabalho, por esses apresentarem um diferencial e, consequentemente, agregarem valor à organização.

\section{Referências}

ARROYO. D. M. P; ROCHA. M.S.P.M.L. Meta avaliação de uma extensão universitária: um estudo de caso. In: REVISTA DE AVALIAÇÃO DE ENSINO SUPERIOR, 2010. Vol. 15. 
Campinas. Disponível em: $\quad$ http://www.scielo.br/scielo.php?script=sci_arttext\&pid=

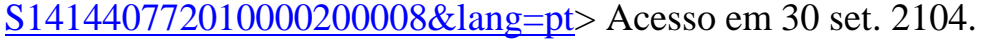

BIROCHI, René. Reflexões sobre a estrutura curricular para a educação superior: a necessidade de uma revisão no curso de administração a partir de um enfoque transdisciplinar. Caderno de Pesquisas em Administração, v.7, n.4, p. 81-91, 2000.

BRASIL. Lei n 9.394, de 20 de dezembro de 1996.

CORRÊA, Dalila Alves. A emergência de um perfil profissional transformador na Administração. VIII ENANGRAD, Rio de Janeiro e Niterói, 1997. Disponível em $<$ http://www.angrad.com/angrad/pdfs/viii_enangrad/A\%20emergencia\%20de\%20um\% 20perfil.PDF >. Acesso em: 09 out. 2001.

CRESWELL, John W. Projeto de pesquisa: métodos qualitativo, quantitativo e misto. 3.ed. Porto Alegre: Artmed, 2010.

FGV. Ebape (São Paulo, SP). Fluxograma das disciplinas e seus pré-requisitos- ingressantes a partir de 2011. Disponível em: 〈http://ebape.fgv.br/sites/ebape.fgv.br/files/ fluxograma-pre-requisitos-a-partir-2011.pdf> Acesso em $10 \mathrm{dez} .2104$.

FISCHER, Tânia. A Formação do Administrador Brasileiro Na Década de 90: Crise, Oportunidade e Inovações nas Propostas de Ensino. Revista de Administração Pública, v.27, n.4, p.11-20, 1993.

GUERRA, Elaine Linhares de Assis. O ensino superior de Administração no Brasil: desafios do novo milênio. XII ENANGRAD, São Paulo, 2001. Disponível em: $<<$ http://www.angrad.com/angrad/pdfs/xii_enangrad/O\%20ensino\%20superior\%20de\%20Administrac ao\%20no\%20Brasil.pdf>. Acesso em: 09 out. 2001.

MEC. Conselho Nacional de Educação (Distrito Federal). José Carlos Almeida da Silva; Lauro Ribeiro Zimmer. Referencial para as Diretrizes Curriculares Nacionais - DCN dos Cursos de Graduação. Disponível em: 2003/pces067 03.pdf> Acesso em 10 dez. 2014.

MOREIRA. F.M; QUEIROZ. T.R; MACINE. Nayele; CAMPEÃO. G. H. Os alunos de administração estão em sintonia com o mercado de trabalho? In: REVISTA DE AVALIAÇÃO DE ENSINO SUPERIOR, 2014. Vol. 19. Campinas. Disponível em: $<$ http://www.scielo.br/scielo.php?script=sci_arttext\&pid=S141440772014000100004\&lang=pt $>$

Acesso em 29 out. 2104.

NICOLINI, Alexandre. Qual será o futuro das fábricas de administradores? In: $25^{\circ}$ Encontro da Associação Nacional dos cursos de Pós-graduação em Administração - ANPAD, 2001. Campinas SP, 16-19/9/2001. Anais.... Rio de Janeiro: ANPAD, 2001 - CD-ROM.

. O futuro administrador pela lente das novas Diretrizes Curriculares: cabeças "bem-feitas" ou "bem cheias"? In: $26^{\circ}$ Encontro da Associação Nacional dos cursos de Pós-graduação em Administração - ANPAD, 2001. Salvador - BA, 22-25/9/2002. Anais.... Rio de Janeiro: ANPAD, 2002 - CD-ROM.

PERES. C.M; ANDRADE. A.S; GARCIA. S.B. Atividades extracurriculares: multiplicidade e diferenciação necessárias ao currículo. In: REVISTA BRASILEIRA DE EDUCAÇÃO MÉDICA, 2007. Vol. 31. Rio de Janeiro. Disponível em: 〈http://www.scielo.br/scielo.php?script=sci_arttext\&pid=S010055022007000300002\&lang=pt> Acesso em 29 out. 2104. 
RICHARDSON, Roberto Jarry. Pesquisa Social: métodos e técnicas. 3.ed. São Paulo: Atlas, 2007.

SEVERINO. Antônio. Expansão do ensino superior: contexto, desafios, possibilidades. In: REVISTA DE AVALIAÇÃO DE ENSINO SUPERIOR, 2009, Campinas. Vol. 14. Disponível em: $<$ http://www.scielo.br/scielo.php?script=sci_arttext\&pid=S1414-40772009000200002 \&lang=pt> Acesso em 30 set. 2104.

SPERS, Valéria Rueda Elias. A educação e o contexto atual. In: In: SPERS, Valéria Rueda Elias; SIQUEIRA, Elisabete Stradiotto; PIZZINATTO, Nadia Kassouf [et al.] (orgs.). Administração: Evolução, Desafios, Tendências. São Paulo: Cobra, 2001.

UERR. Curso de ciência da computação (Boa Vista, RR). Atividades complementares. Disponível em: 〈http://www.uerr.edu.br/cursos/cc/index.php/atividades-complementares $>$ Acesso em 29 out. 2104.

UFC. Curso Administração (Fortaleza, CE). Currículo. Disponível em: $<$ http://www.si3.ufc.br/sigaa/public/curso/curriculo.jsf;jsessionid=04C31726F29A34BA15F27C89D8 8EF949.node142> Acesso em 10 dez. 2014.

UFMG. Faculdade de ciências econômicas (Belo Horizonte, MG). Disponível em: <http://web.face.ufmg.br/face/portal/informacoes-aos-alunos.html > Acesso em 10 dez. 2014.

UFRGS. Administração (Porto Alegre, RS). Grade curricular. Disponível em: $<$ http://www.ufrgs.br/ufrgs/ensino/graduacao/cursos/exibeCurso?cod curso=298 $>$ Acesso em $10 \mathrm{dez}$. 2014.

UFRPE. Curso administração (Recife, PE). Marco Aurélio Benevides Pinho. Administração. Disponível em: <http://www.ufrpe.br/curso_ver.php?idConteudo=26> Acesso em 10 dez. 2014.

ULBRA. Campus Canoas (Canoas, RS). Atividades acadêmicas. Disponível em: <http://www.ulbra.br/letras/atividades-academicas > Acesso em 29 out. 2104.

UNIVASF. Projeto pedagógico do curso de Administração. 2008.

Curso Administração (Petrolina, PE). Resolução atividades complementares. Disponível em: 〈http://proex.univasf.edu.br/diretoria-de-extens\%C3\%A3o/>. Acesso em 18 dez. 2014.

\section{Como citar este artigo (Formato ABNT):}

CASSUNDÉ, F.R.S.A.; SANTOS, A.C.G.B.; MURANAKA, E.N.; NUNES, L.A.; AMORIM, R.N. Participar ou não participar, eis a questão! Um estudo sobre o engajamento dos estudantes de Administração em atividades extracurriculares. Id on Line Revista de Psicologia, Abril de 2015, vol.9, n.26, Supl. Esp. p. 42-56. ISSN 1981-1189.

Recebido: 10/01/2015

Aceito: 22/01/2015 